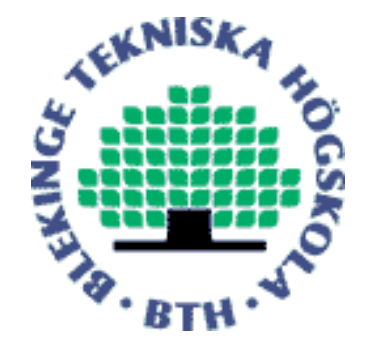

Copyright (C) 2013 IEEE.

Citation for the published paper:

A framework for software usability \& user experience measurement in mobile industry

Jia Tan, Kari Rönkkö, Cigdem Gencel

Joint Conference of the 23rd International Workshop on Software Measurement and the 8th International Conference on Software Process and Product Measurement, IXICA M MENTITID A

2013 Ankara

This material is posted here with permission of the IEEE. Such permission of the IEEE does not in any way imply IEEE endorsement of any of BTH's products or services Internal or personal use of this material is permitted. However, permission to reprint/republish this material for advertising or promotional purposes or for creating new collective works for resale or redistribution must be obtained from the IEEE by sending a blank email message to pubs-permissions@iee.org.

By choosing to view this document, you agree to all provisions of the copyright laws protecting it. 


\section{A Framework for Software Usability \& User Experience Measurement in Mobile Industry}

\author{
Jia Tan, Kari Rönkkö \\ Blekinge Institute of Technology, \\ Karlskrona, Sweden \\ tanjia81@yahoo.com, kari.ronkko@bth.se
}

\author{
Cigdem Gencel \\ Free University of Bolzano, \\ Bolzano (Bozen), Italy \\ cigdem.gencel@unibz.it
}

\begin{abstract}
The mobile industry faces challenges in designing software usability and user experience (UX) measurement instruments. The major difficulties arise due to: 1) diversity of definitions and terminology used for usability and UX aspects and attributes, which lead to inconsistencies, and 2) lack of a taxonomy for these attributes with links to well-defined measures in the literature. In this paper, we present a framework to support mobile industry to overcome these challenges. We first unified the terminology and definitions for usability and UX attributes in the literature. Then, we created taxonomy of attributes and sub-attributes. By using the well-known Goal Question Metric (GQM) approach, we identified a comprehensive set of questions and measures for each attribute that could be used as a basis for developing measurement instruments. The framework was evaluated through a case study conducted in a usability research, development and consultancy company for mobile industry in Sweden.
\end{abstract}

Keywords—software usability; user experience; Goal Question Metric; evaluation; measurement; case study; mobile industry

\section{INTRODUCTION}

During the last decade, mobile phones and applications have become one of the most popular mass-market products. The mobile industry has to deal with challenges of increasing functionality requirements of the users as well as their demand for high quality. In order to survive in the highly competitive market, mobile development companies not only should satisfy the requirements of users but also provide more: a satisfying experience.

Kirakowski et al. [1] identified three interdependent aspects to be considered when evaluating technology: i) the product, ii) interaction between the user and the product (usability), and iii) experience of using the product (user experience). This paper deals with usability and user experience (UX) aspects.

Usability takes an objective view of quality; the hallmark of usability testing methods primarily rests on observation or measurement when participants interact with a product.

On the other hand, UX highlights non-utilitarian aspects of such interactions, shifting the focus to user affect and sensation. Since UX is subjective, it may not matter how good a product is objectively; its quality must also be "experienced" subjectively to have impact. And, several aspects can influence how people perceive quality during the interaction with the product.
There are a number of measures, instruments and tools developed for measuring usability and UX. However, the definitions for usability and UX vary significantly in software engineering (SE) community [2][3]. In addition, UX is an intriguing notion, which has been widely disseminated and is increasingly accepted in the Human-Computer Interaction (HCI) community as well. The independent efforts put forth by these two separate communities have further increased the diversity in the definitions and inconsistencies in terminology, and hence inconsistencies in understanding and measurement (see Section II and Appendix). Therefore, different organizations use different measures and instruments for evaluating their products, which does not allow comparability.

Furthermore, even though a few standards (such as [4], [5]) have been developed to enable standardization, they are not being widely used when developing measurement instruments. One identified reason is the lack of experts in these areas [6]. In addition, there is a wide gap between academic studies and industrial practice [7], which does not support development of measurement and evaluation instruments.

In order to address some of these challenges, we developed a framework [8] to support mobile industry when designing usability and UX measurement instruments and, thereby reliably compare their products. We tested the framework in a mobile application development company, where a measurement instrument that meets the needs of the company was developed using the framework.

This paper is organized as follows: In Section II, background work on usability, UX and evaluation methods is presented. Section III presents the developed framework, and Section IV, the case study. Finally, the conclusions are given in Section V.

\section{BACKGROUND}

Traditional usability definition strongly focuses on users' tasks and their accomplishment; that is, more on the pragmatic side of the user-product relationship. On the other hand, UX represents a holistic view of the pragmatic aspects and hedonic aspects of product possession and use such as beauty, challenge, stimulation, or self-expression [9].

Usability considers barriers, problems, frustration, stress and other negative aspects, and their removal. On the other hand, UX often stresses the importance of positive outcomes of 
technology use or possession; be it positive emotions such as joy, pride, and excitement or simply "value" [10].

As UX is associated with a broad range of fuzzy concepts related to emotion, affection, experience, hedonic and aesthetic, this creates difficulty in getting a universal definition for UX. Some examples of so-called elemental attributes of UX proposed by Cockton [11] are fun, pleasure, pride, joy, surprise, and intimacy. And these are just a subset of a growing list of human values.

Roto \& Kaasinen [12] propose that UX is a term that describes user's feelings towards a specific product, system, or object during and after interacting with it. Various aspects influence the feelings, such as user's expectations, the conditions in which the interaction takes place, and the system's ability to serve user's current needs. According to Jetter \& Gerken [13], UX incorporates not only the traditional qualities like reliability, functionality, or usability but also novel and hard-to-grasp concepts from visual or industrial design, psychology or marketing research, e.g. attractiveness, stimulation, fun, "coolness", "sexiness" or the successful delivery of a brand proposition.

There are a number of researchers who investigated UX components [9][14][15][16][17]. They found out that there is a wide agreement that user's earlier experiences and expectations as well as the context of use affect UX.

Hassenzahl [18] proposed a complex model, which defined key elements of UX and their functional relations. The author distinguished the difference between pragmatic and hedonic attributes in his model. Later, Hassenzahl \& Tractinsky [9] defined three high level components, which are able to cover all aspects mentioned above. In [12][19], these three components are taken as a starting point and a set of attributes related to each component are identified. The first component is the System, which involves product, object, service, infrastructure and people, the complexity, purpose, usability, functionality as the characteristics of the designed system. The second component is the Context, which includes physical context, social context, temporal context and task context. The last component is the User, which considers user's needs, the available mental and physical resources, emotional state, earlier experience and expectations.

There are various usability and UX evaluation methods in the literature, which were categorized by [20] as: a) user-based evaluation methods [21] such as user-administered questionnaires, observing users and empirical usability testing; b) inspection-based evaluation methods [22] such as heuristic evaluation, guideline-based methods, cognitive walkthrough and heuristic walkthrough; and c) model-based evaluation methods [23] such as task network model.

A number of studies in the literature show that usability is usually measured subjectively, and often not in a consistent way [24][25][26][27]. Evaluation of usability in this manner results in inconsistent results about the usability [28], or else incomparability of the test results of products.

\section{A FRAMEWORK SUPPORT FOR USABILITY AND UX MEASUREMENT}

In this section, we present the details of the developed framework, which has two main components: 1) A taxonomy for usability and UX attributes, and 2) A generic questions and measures set for developing measurement instruments.

\section{A. A Taxonomy For Usability and UX Attributes}

In order to develop the framework, we first defined a taxonomy for usability and UX attributes. Performing a comprehensive literature review, we explored the definitions and terminology for usability and UX attributes. We used the snowball approach when performing the literature review. We started by reviewing the standards discussed in [29] as the base for our further exploration. Then, by analyzing the results, we came up with a list of attributes with unified definitions and terminology. In the framework, we chose to use the definitions of the standards recognized by the community (see Appendix Table $3 \&$ Table 4 for the definitions in the literature).

Finally, we defined a taxonomy of attributes and associated sub-attributes by identifying the nature of the relationship among them (see Table 1). In total, we identified 9 main attributes and 27 associated sub-attributes. For example, the sub-attributes; Time behavior, Resource utilization, Operability, Minimal action, Feedback, Minimal memory load and Navigability are dimensions of Efficiency attribute. From the perspective of sub-attributes, for example, Attractiveness is related to two main attributes: Satisfaction and Generalizability. On the other hand, Understandability has no relation to any sub-attributes identified.

\section{B. A Generic Questions And Measures Set For Developing Measurement Instruments}

The framework was developed with the aim to support companies for developing their usability and UX evaluation instruments. Therefore, as the second step, we defined a generic set of questions and measures, which mobile companies can use in developing their usability and UX evaluation methods.

To this end, we used the well-known Goal Question Metric (GQM) paradigm [30][31]. GQM is a top-down approach used in identifying the required measures in a company based on the organizational or business goals. For the purposes of this study, however, we used the GQM approach for another purpose than how it is used traditionally.

As the framework was to be generic to allow designing measurement instruments for any mobile development company, we first defined generic top-level goals for the 9 usability and UX main attributes of mobile applications. For example, one top-level goal was "to assess usability and UX for a specific software product from the user's point of view in the context of mobile applications". 


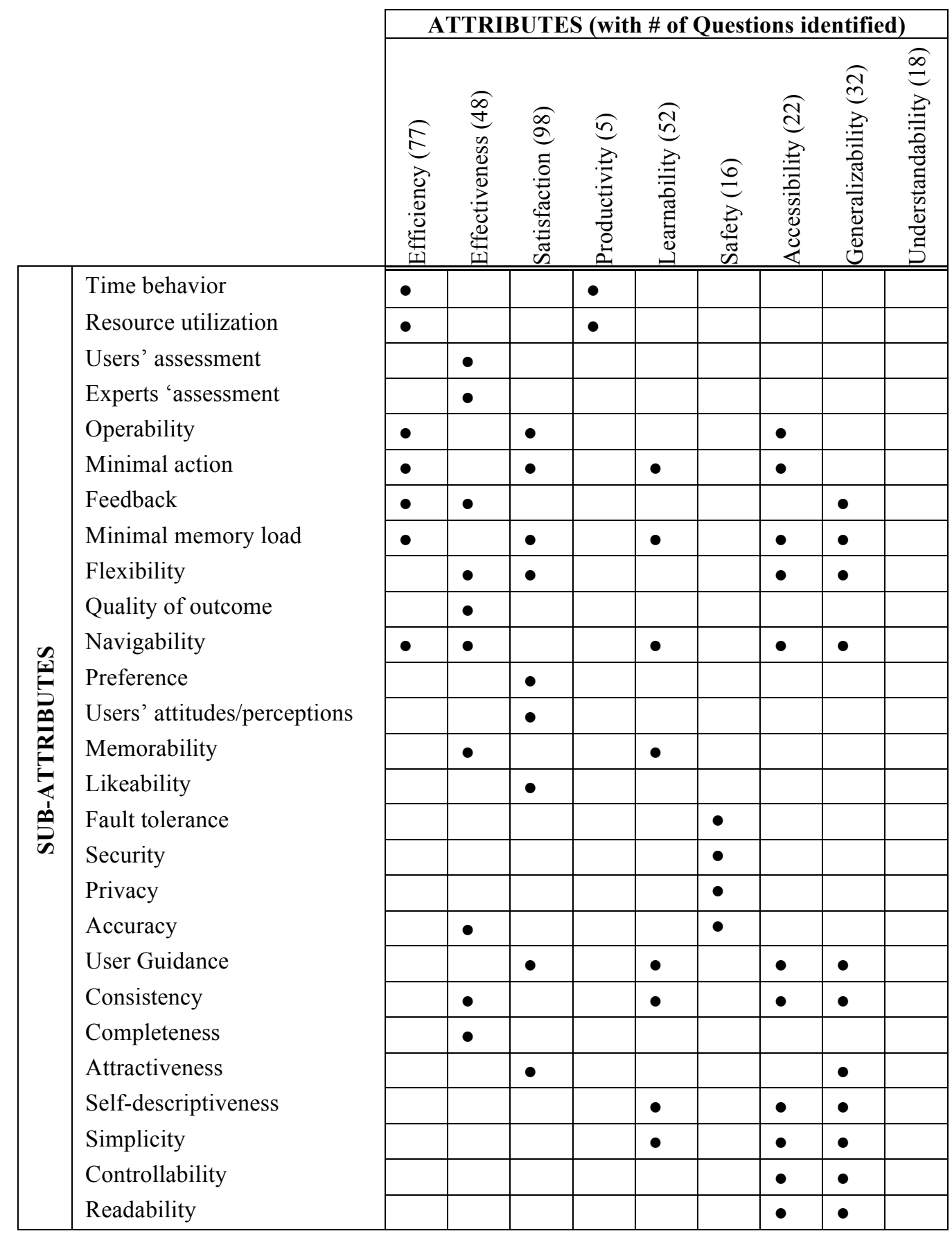

Then, we identified sub-goals for each main attribute/sub-attribute pair in the taxonomy. For example, one sub-goal was defined for Efficiency-Time Behavior and another for Learnability-Minimal action. In total, we defined 63 sub-goals.

Later, we defined a set of questions that can be used by mobile companies as part of measurement instruments as these correspond to information needs of the stakeholders.
We also included in the framework a couple of questions companies have already been using. For the main 9 main attribute/27 sub-attribute pairs, we defined in total 368 questions (Efficiency: 77, Effectiveness: 48, Satisfaction: 98, Productivity: 5, Learnability: 52, Safety: 16, Accessibility: 22, Generalizability: 32, Understandability: 18) as shown in Table 1 . 
Finally, we associated the measures found in the literature review to the questions. To answer each question, we added both objective and subjective measures that we identified in the literature. We present a few examples in Table 2 .

\section{TABLE 2. EXAMPLE QUESTIONS AND MEASURES FOR USABILITY AND UX EVALUATION}

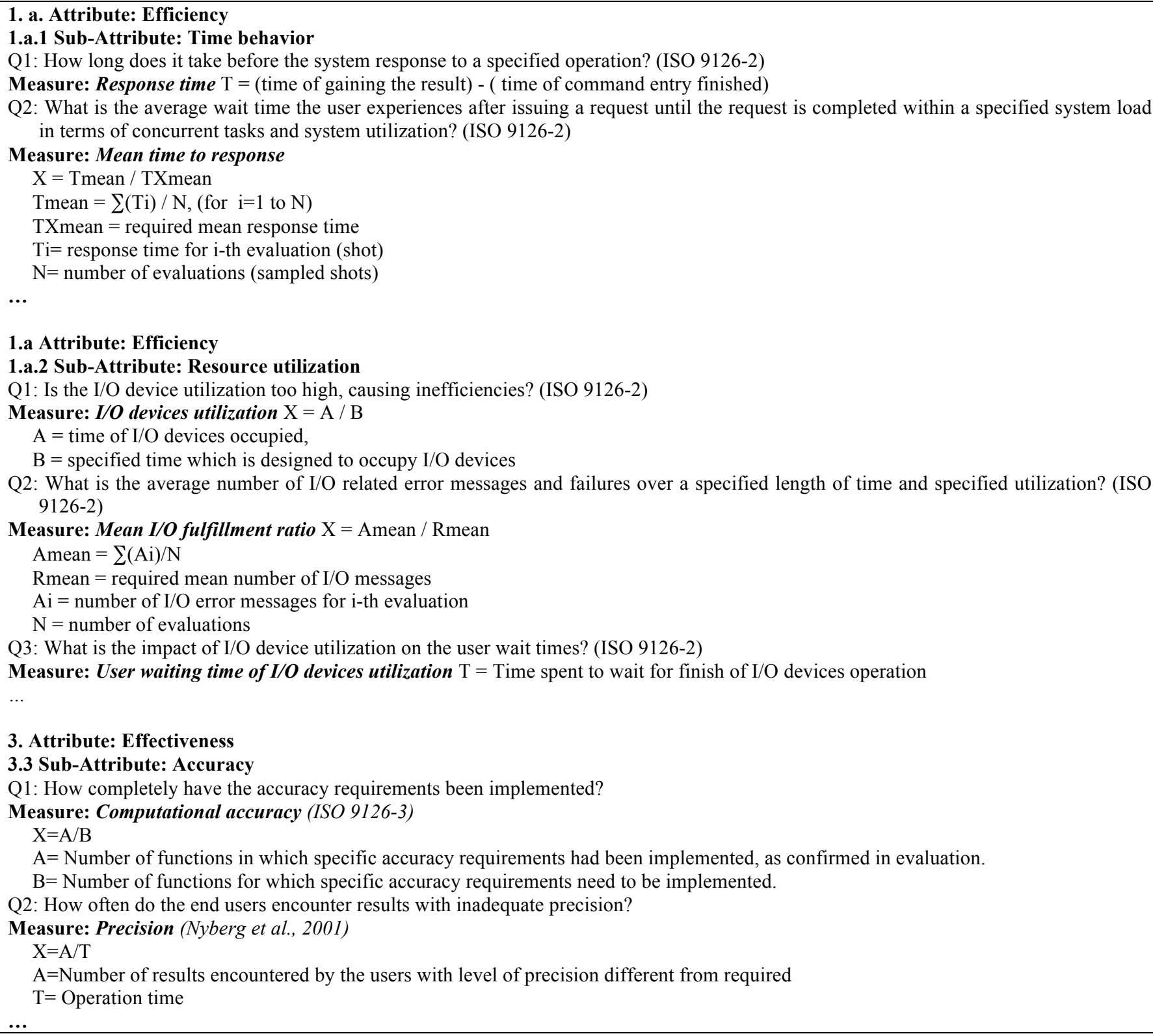

\section{CASE STUDY}

In order to evaluate the framework, we conducted a case study in a small telecom company. Our research question for this case study was as follows: "Does the framework provide improvement by supporting the design of usability and UX evaluation instruments?"

We designed this case study as a single-case study [32] as the case company and the selected application are representative and typical in software mobile industry.
The case company was Adduce AB, a Swedish research, development and consultancy company that was established in early 2009. Adduce AB mainly provides four services: Adduce Research, Adduce Studios, Adduce Consulting and Adduce Courses. The research part focuses on developing the Adduce toolbox, which would provide clients to drive, prove and maintain high-level of usability in their products. Adduce Studio mainly works on producing fun and innovative mobile applications and games. And finally, the company also offers expert consultancy in the area of 
usability, UX, product management and software development.

\section{A. Case Study Conduct}

The case company decided to use one of the recent applications; BodyJournal application installed on iPod 8GB product (model number: A1288), as the case application. The main purpose of developing this application was to help people to keep fit and healthy by controlling daily calories gaining and burning amount

For this case study, as the usability evaluation method, we used User-based evaluation method [21] - a combination of Questionnaire approach and Observing Users approach [33]. For the UX, we used a combination of Questionnaire approach and Narration approach [34][35].

To develop the measurement instruments, we tailored the framework for the needs of the company and the case application in an iterative by also involving the CEO of the company, who himself is a usability measurement expert. He has ten years of professional work experience on usability research. In the past, he worked as usability researcher, test leader, interaction design manager, and product strategy manager.

The experts decided to evaluate a number of use cases. At the end, two usability evaluation questionnaires were developed for each (one with 67 statements using a likertscale from 1 to 5 for the end-user to fill in while each use case is conducted and the other with 27 questions selected from the framework for the test leader to make measurements while observing the user during the tests).

These two forms evaluate 8 of the usability subattributes; that is, Effectiveness, Efficiency, Productivity, Learnability, Accessibility, Generalizability, Understandability and Safety. The ninth usability subattribute, Satisfaction was evaluated through an overall satisfaction and UX evaluation form. In total, 19 statements were selected from the framework and customized for the BodyJournal application, which ended up with 10 statements in the form.

Later, we used these instruments during the expert evaluation session. Two participants from the case company were involved at this phase. One of the participants had five years of work experience as usability researcher and test leader, and the second has eight years of experience of method cooperation with industry [36] focusing usability. Both had experience of developing a usability test framework that became a de facto standard in industry with more than 350 employees [37].

The case study was performed in the company offices. One of the participants played the role of the user while the other as the test leader. During the case study, the test leader worked together with the user and the user was encouraged to think aloud to help the test leader to better understand how users were thinking and the motivations behind their behavior.
The test leader observed the user during the tests and made measurements according to the designed questions (e.g recorded the time taken to conduct an individual task; noted errors, and number of attempts to correct errors, observed the user's hesitation from a natural flow of user interaction, recorded time taken to look for help and etc.).

When performing each use case, the user was requested to complete the usability evaluation questionnaire concerning the application in relation to the specific use case just performed. This process was repeated for each use case and in between each use case, the test leader communicated his observations with the user and verified whether his impressions were correct or not. When all 7 use cases were completed, the user was asked to fill in an overall Satisfaction and UX evaluation form, which expresses the user's overall opinion of the application based on the experience.

The data collected during the sessions were summarized using a spreadsheet and presented as graphs to show the overall satisfaction.

\section{B. Case Study Results}

The participants of the expert evaluation session stated that the evaluation results of the end-users together with the expert tests provided good indicators regarding the strengths and weaknesses of the current version of the BodyJournal application.

For example, from the end-user evaluations (see Figure 1), it was identified that the Accessibility and Generalizability aspects (such as support for multi-language, interface customization and zooming functions) were not considered for the current design of the application.

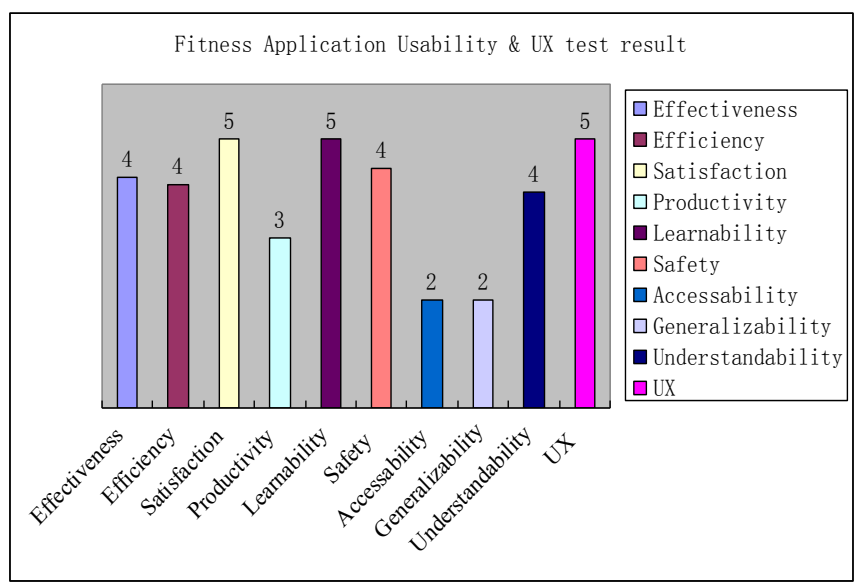

\section{FIGURE 1 BODYJOURNAL APPLICATION USABILITY \& UX TEST RESULTS (END-USERS PERSPECT1VE)}

Furthermore, even though the Learnability and Understandability aspects appeared to be good based on the end-user evaluations, the test results of the experts regarding two of the use cases showed that the grouping and ordering of the menu options were not intuitive for the users, and 
some were confusing. Therefore, the experts decided to redesign the task flow for these use cases. The test results also indicated that it was necessary to check the calculation accuracy of adding activity function. The details of the test results can be found in [8].

One important result from the usability evaluation to improve the measurement and evaluation instruments was the need to further categorize the use cases according to their relationship to the specific aspects of usability and domain, and that the questions can benefit from being split according to the chosen use cases. This work needs to be done iteratively by applying industry.

On the other hand, the case study has some validity threats that require to be discussed. The case application was evaluated in one company for a single case product. Therefore, it is hard to generalize the results for other companies and cases. But, we believe that the study is strong in when it comes to conclusion validity, i.e. the degree to which conclusions we reach about relationships in our data are reasonable among professionals in the domain of usability and UX.

\section{CONCLUSIONS}

This paper presented a framework for supporting development of usability and UX measurement instruments.

The framework provides a unified terminology and taxonomy for usability and UX attributes sub-attributes. Furthermore, incorporating a generic set of questions and related measures, the framework serves as a guideline for mobile companies on how to trace and interpret the collected data on the usability and UX of their products. The collected data based on visible goals can eventually lead to better decisions to improve the usability and the UX of the mobile industry products.

Furthermore, during our discussions with the participants of the case study, we identified the significance of addressing context of use regarding usability measurement that requires further investigation. Also, in most cases, usability and UX measurements are still put in the late stage of software product development and there is a need to find a way to shift it to the early stage of development life cycle. A promising future work identified is the extension of the framework to help in identifying the relationship between usability and UX attributes and their relevant measures that could be used at different phases in the life cycle. This information might be used to develop evaluation methods early in the life cycle so that the final product usability and UX will be improved.

\section{REFERENCES}

[1] Kirakowski, J., and McNamara, N., 2006. Functionality, usability and user experience: Three areas of concern. In Interactions, Vol.13 (6), pp.26-28.

[2] Abran, A., Laila C., Witold S., 2006. Harmonization of usability measurements in IS09126 software engineering standards, IEEE ISIE 2006, Canada.

[3] Seffah, A., Mohammad D., Rex B.K.,Harkirat K.P., 2006. Usability measurement and metrics: A consolidated model, In Software Quality
Journal, Springer Science, Volume 14, No 2.

[4] ISO/IEC, 2001. ISO/IEC 9126-1 Standard, Software Engineering, Product Quality, Part 1: Quality Model.

[5] ISO, 1998. ISO 9241-11, Ergonomic Requirements for Office Work with Visual Display Terminals (VDTs), Part 11: Guidance on usability, Geneva: Author.

[6] Bevan, N., 2009. International Standards for Usability Should Be More Widely Used, Journal of usability Studies, May 2009: Volume 4, Issue 3.a

[7] Gulliksen, J., Boivie, I., Persson, J., Hektor, A., Herulf, L., 2004. Making a difference - a survey of the usability profession in Sweden, In Proc.of the third Nordic Conf. on HCI Finland, Vol 82, ACM, Pages: $207-215$.

[8] Tan, J. 2009. FOUUX-A Framework for usability \& User Experience. MSc Thesis (MSE-2009-23), Blekinge Institute of Technology, Sweden.

[9] Hassenzahl, M., Tractinsky, N., 2006. User Experience - A Research Agenda. Behaviour and Information Technology, Vol. 25, No. 2, March-April 2006, pp. 91- 97

[10] Cockton, G., 2004. From quality in use to value in the world. In Proceedings of the CHI 04 Conference on Human Factors in Computing Systems. Extended abstracts. New York, NY, pp. 12871290.

[11]Cockton, G., 2006. Valuing user experience, In Proceedings of the NordiCHI2006 Workshop"User Experience: Towards a Unified View", Oslo, Norway, pp.100-105.

[12] Roto, V. \& Kaasinen, E., 2008. The second international workshop on mobile internet user experience. In Proc. of the 10th intern. Conf. on HCI with mobile devices and services, ACM. Amsterdam, The Netherlands.

[13] Hans-Christian Jetter, J. G., 2006. A Simplified Model of User Experience for Practical Application. The 2nd COST294-MAUSE International Open Workshop, 14 October 2006. Norway.

[14] Mäkelä, A., Fulton Suri, J., 2001. Supporting Users' Creativity: Design to Induce Pleasurable Experiences. Proceedings of the International Conference on Affective Human Factors Design, pp. 387-394.

[15] Hiltunen M., Laukka M., Luomala J., 2002. Mobile User Experience. IT Press, Finland.

[16] Forlizzi, J., Ford, S., 2000. The Building Blocks of Experience: An Early Framework for Interaction Designers. Proceedings of Designing Interactive Systems (DIS 2000). New York City, USA.

[17] Arhippainen, L., Tähti, M., 2003. Empirical Evaluation of User Experience in Two Adaptive Mobile Application Prototypes. In: Proc. of the 2nd Intern. Conf. on Mobile and Ubiquitous Multimedia, Norrköping, Sweden.

[18] Hassenzahl, M., 2003. The thing and I: understanding the relationship between user and product. In Funology:From usability to Enjoyment, M.Blythe, C.Overbeeke, A.F.Monk, \& P.C. Wright (Eds.), pp.31-42, Dordrecht: Kluwer.

[19] Roto, V., 2006. User Experience Building Blocks. The 2nd COST294MAUSE International Open Workshop, 14 October 2006. Norway.

[20] Sears, A., Jacko, Julie A., 2003. The human-computer interaction handbook: fundamentals, evolving technologies, and emerging applications, Lawrence Erlbaum Associates, Inc., Publishers, New Jersey, ISBN 0-8058-4468-6.

[21] Dumas, J., 2003. User-Based Evaluations, In Sears, A., Jacko, Julie A., The human-computer interaction handbook: fundamentals, evolving technologies, and emerging applications, Lawrence Erlbaum Associates, Inc., Publishers, New Jersey.

[22] Cockton, G.,Lavery, D., Woolrych, A., 2003. Inspection-Based Evaluations, In Sears, A., Jacko, Julie A., The human-computer interaction handbook: fundamentals, evolving technologies, and emerging applications, Lawrence Erlbaum Associates, Inc., Publishers, New Jersey.

[23] Kieras, D., 2003. Model-Based Evaluation, In Sears, A., Jacko, Julie A., The human-computer interaction handbook: fundamentals, evolving technologies, and emerging applications, Lawrence Erlbaum Associates, Inc., Publishers, New Jersey.

[24] Virzi,R.A., 1990. Steamlining the design process: Running fewer subjects. Proceedings of the Human Factors Society, 34th Annual Meeting, Santa Monica, CA: Human Factors and Ergonomics Society, pp.291-294. 
[25] Virzi,R.A., 1992. Refing the test phase of usability evaluation: How many subjects is enough? Human Factors, 34,457-468.

[26] Lewis, J., 1994. Sample size for usability studies: Additional considerations. Human Factors, 36, 368-378.

[27] Molich, R. et al., 2001. Handheld applications design: merging information appliances without affecting usability. In: Proceedings of IFIP TC.13 Conference on Human-Computer Interaction. IOS Press, Amsterdam, pp. 391-398.

[28] McGee, M., 2004. Master usability Scaling: Magnitude Estimation and Master Scaling Applied to usability Measurement, In Proc. of the SIGCHI Conf. on Human factors in computing systems, Austria, pp 335-342.

[29] Bevan, N., 2001. International standards for HCI and usability. In International Journal of Human-Computer Studies, 55 (4) pp. 533-552.

[30] Basili, V.R, and Weiss, D.M. 1984. A Methodology for Collecting Valid Software Engineering Data. IEEE Transactions on Software Engineering, Vol.SE-10, no.6, pp. 728-738.

[31] Basili, V.R, and Rombach, H.D. 1988. The TAME Project: Towards Improvement-Oriented Software Environments. IEEE Transactions on Software Engineering. SE-14 No.6, pp. 758-773.

[32] Yin, R. K. 2009. Case study research: design and methods, 4th ed. London: SAGE.

[33] Baber,C., \& Stanton,N., 1996. Observation as a technique for usability evaluation, In P.Jordan, B.Thomas, B. Weerdmeester, \& I. McClelland (Eds.), usability evaluation in industry, London: Taylor \& Francis, pp. 85-94.

[34] Arjan Geven, J. S., Manfred T., 2006. Narrations and Storytelling as methodological key elements for studying user experience. Workshop on User Experience - Towards a Unified View. In conjuction with NordiCHI 2006 conference. Oslo, Norway. pp. 79-83.

[35] Hassenzahl, M., 2003. The thing and I: understanding the relationship between user and product. In M.Blythe, C.Overbeeke, A.F.Monk, \& P.C. Wright (Eds.), Funology:From usability to Enjoyment (pp.31-42), Dordrecht: Kluwer.

[36] Dittrich, Y., Rönkkö, K., Lindeberg, O., Erickson, J. and Hansson, C., 2008. Cooperative method development: Combining qualitative empirical research with method, techniqueand process improvement, In the Journal of Empirical Software Engineering, 13(3), pp.231-260.

[37] Rönkkö, K., Winter, J., and Hellman, M. 2009. Usability and User Research: Eight years of research and method development cooperation, Technical Report, Blekinge Institute of Technology.

[38] Molich, R. User-Friendly Web Design (in Danish). Copenhagen: Teknisk Forlag, 2000 Nyberg, M., Bjork, S., Goldstein, M., Redström, J., 2001. Handheld applications design: merging information appliances without affecting usability. In: Proc. of IFIP TC.13 Conf. on Human-Computer Interaction. IOS Press, Amsterdam, pp. 391398.

[39] Bevan, Nigel and Macleod, Miles, 1994: usability Measurement in Context. In Behaviour and Information Technology, 13 (1) pp. $132-$ 145 .

[40] Macleod, M., and Rengger, R., 1993. The development of DRUM: A software tool for video-assisted usability evaluation. Retrieved July 3,
2005 from http://www.usability.serco.com/papers/drum93.pdf

[41] Kirakowski, J. and Corbett, M., 1993. SUMI: The Software usability Measurement Inventory, British Journal of Educational Technology 24: $210-212$.

[42] Bevan, N., 1995. Human-Computer Interaction Standards. In: Proceedings of the Sixth International Conference on HumanComputer Interaction. pp. 885-890.

[43] Macleod, M., Bowden, R., Bevan,Nigel. and Curson, I., 1997. The MUSiC Performance Measurement Method. In Behaviour and Information Technology, 16 (4) pp. 279-293.

[44] ISO/IEC, 2004. ISO/IEC 9126-4, Software Engineering, Product Quality, Part 4: Quality in Use Metrics, Geneva:Author.

[45] McCall, J. A., Richards, P. K., and Walters, G. F., 1977. Factors in Software Quality, Springfield, VA: National Technical Information Service.

[46] Preece, J., Rogers, Y., Sharp, H., Benyon, D., Holland, S., and Carey, T. 1994. Human Computer Interaction, Wokingham, UK: AddisonWesley, pp.775.

[47] Dix, A., Finlay, J., Abowd, G., Beale, R., 1993. Human-computer interaction. Prentice-Hall, New York, NY, pp.600.

[48]Lin, H. X., Choong, Y.-Y., and Salvendy, G., 1997. A proposed index of usability: A method for comparing the relative usability of different software systems, Behaviour and Information Technology, 16: 267277.

[49] Olsina,L., Lafuente,G., and Rossi, G., 2001. Specifying quality characteristics and attributes for websites, in S. Murugesan and Y. Deshpande (Eds.), Web Engineering,

[50] Rubin,J., 1994, Handbook of usability testing, NY: John Wiley.

[51] Czerwinski, M.P., van Dantzich, M., Robertson, G., Hoffman, H., 1999. The contribution of Thumbnail image, mouse-over text and spatial location memory to web page retrieval in 3D. In: Proceedings of IFIP TC.13 Intern. Conf.on Human-Computer Interaction. IOS Press, Amsterdam, pp. 163-170.

[52] Preece, J.,Keller,L., 1990. Human-Computer Interaction, Cambridge, UK: University Press, pp.437.

[53] ISO, 1996. ISO 9241-10, Ergonomic Requirements for Office Work with Visual Display Terminals, Part 10: Dialogue principles, Geneva: Author.

[54] ISO/IEC, 1995. ISO/IEC 12207, Information technology - Software life cycle processes.

[55]Hornbæk, K., 2006. Current practice in measuring usability: Challenges to usability studies and research, International Journal of Human-Computer Studies 64, 79-102.

[56] Rui, Y., Gupta, A., Cadiz, J., 2001. Viewing meeting captured by an Omni directional camera. In: Proc.of ACM Conference on Human Factors in Computing Systems. ACM Press, New York, NY, pp. 450 457.

[57] Wang, Q.Y., Shen, M.W., Shui, R., Su, H., 2001. Detectability and comprehensibility study on audio hyper-linking methods. In: Proc. of IFIP TC.13 Intern. Conf. on Human-Computer Interaction. IOS Press, Amsterdam, pp. 310-317. 


\section{APPENDIX}

\section{TABLE 3. USABILITY AND UX ATTRIBUTES DESCRIPTION}

\begin{tabular}{|c|c|}
\hline Attributes & Sources \\
\hline Efficiency & {$[3][5][38][39][40][41][42][43]$} \\
\hline \multicolumn{2}{|c|}{$\begin{array}{l}\text { "The capability of the software product to provide appropriate performance, relative to the amount of resources used, under stated conditions." } \\
\text { [3]. }\end{array}$} \\
\hline Effectiveness & {$[4][40][41][42][43][44][45]$} \\
\hline \multicolumn{2}{|c|}{$\begin{array}{l}\text { "The capability of the software product to enable users to achieve specified tasks with accuracy and completeness in a specified context of } \\
\text { use." [44]. }\end{array}$} \\
\hline Satisfaction & {$[4][38][39][41][42][43][44][46]$} \\
\hline \multicolumn{2}{|c|}{ "Satisfaction measures assess the user's attitudes towards the use of the product in a specified context of use." [44]. } \\
\hline Productivity & {$[40][43][44]$} \\
\hline \multicolumn{2}{|c|}{$\begin{array}{l}\text { "The capability of the software product to enable users to expend appropriate amounts of resources (i.e. time to complete tasks, user efforts, } \\
\text { materials or financial cost of usage) in relation to the effectiveness achieved in a specified context of use." [44]. }\end{array}$} \\
\hline Learn-ability & {$[3][38][40][41][42][43][45][46][47][48]$} \\
\hline \multicolumn{2}{|c|}{ "The capability of the software product to enable the user to learn its application." [3] } \\
\hline Safety & {$[44]$} \\
\hline \multicolumn{2}{|c|}{$\begin{array}{l}\text { "Safety metrics assess the level of risk of harm to people, business, software, property or the environment in a specified context of use. It } \\
\text { includes the health and safety of the both the user and those affected by use, as well as unintended physical or economic consequences." } \\
\text { [44]. }\end{array}$} \\
\hline Accessibility & [49] \\
\hline \multicolumn{2}{|c|}{ The capability of a software product to be used by persons with some type of disability (e.g., visual, hearing). } \\
\hline \multicolumn{2}{|c|}{ Generalizability } \\
\hline \multicolumn{2}{|c|}{$\begin{array}{l}\text { This attribute concerns whether a software product accommodates different kinds of users with different cultural backgrounds, gender, age and } \\
\text { etc. }\end{array}$} \\
\hline Understandability & {$[3][38]$} \\
\hline
\end{tabular}

\section{TABLE 4. USABILITY AND UX SUB-ATTRIBUTES DESCRIPTION}

\begin{tabular}{|c|c|}
\hline Sub-Attributes & Description \\
\hline Time behavior & [3][39] \\
\hline \multicolumn{2}{|c|}{$\begin{array}{l}\text { "The capability of the software product to provide appropriate response and processing times and throughput rates when performing its } \\
\text { function, under stated conditions." [1] }\end{array}$} \\
\hline Resource utilization & {$[3][39]$} \\
\hline \multicolumn{2}{|c|}{ "Capability to consume appropriate amounts and types of resources when the software performs its function under stated conditions." [3] } \\
\hline Attractiveness & {$[3]$} \\
\hline \multicolumn{2}{|c|}{ Capability of the software product to be attractive to the user (e.g., through use of color or graphic design) } \\
\hline Operability & {$[3][45]$} \\
\hline \multicolumn{2}{|c|}{ "The capability of the software product to enable the user to operate and control it." } \\
\hline Likeability & {$[3][51]$} \\
\hline \multicolumn{2}{|c|}{ "User's perceptions, feelings, and opinions of the product" [50] } \\
\hline Flexibility & {$[47][48][52]$} \\
\hline \multicolumn{2}{|c|}{ "With flexibility allowing adaptation to some specified percentage variation in tasks and or environments beyond those first specified." [52] } \\
\hline Minimal action & {$[39][40][48]$} \\
\hline \multicolumn{2}{|c|}{ "Capability of the software product to help users achieve their tasks in a minimum number of steps." [48] } \\
\hline Minimal memory load & {$[48]$} \\
\hline \multicolumn{2}{|c|}{$\begin{array}{l}\text { Whether a user is required to keep minimal amount of information in mind in order to achieve a specified task. To ensure minimal working } \\
\text { memory load will increase human performance. Minimal long-term memory load requirement will help users learn interface more easily } \\
\text { The less that users need to learn, the faster users can learn it. }\end{array}$} \\
\hline Memorability & {$[38]$} \\
\hline
\end{tabular}


The concept of memorability, within the usability context, is that a user can leave a software product and, when he or she returns to it, remember how to do things in it.

\begin{tabular}{|l|l|}
\hline Accuracy & {$[3]$} \\
\hline
\end{tabular}

"The capability of software product to provide right or agreed results or effects." [3]

\begin{tabular}{l|l} 
User Guidance & {$[48]$}
\end{tabular}

Whether the user interface provides context-sensitive help and meaningful feedback when errors occur. In general, a computer system with a good user guidance scheme will improve the learnability of the system as well as decrease the mental workload of the users since no extra effort will be needed for the users to perform designated tasks.

\section{\begin{tabular}{l|l} 
Consistency & {$[48]$} \\
\hline
\end{tabular}}

"Degree of uniformity among elements of user interface and whether they offer meaningful metaphors to users." In human computer interaction, consistency is recognized to be able to improve user performance and user satisfaction.

\section{\begin{tabular}{l|l} 
Self-descriptiveness & {$[53]$} \\
\hline
\end{tabular}}

"The capability of the software product to convey its purpose and give clear user assistance in its operation." Self-descriptiveness provides simplicity by reducing users' memory load. Users can retain their capacity for their tasks instead of bothering with the system. They can work more efficiently.

\begin{tabular}{|l|l}
\hline Feedback & {$[3]$} \\
\hline
\end{tabular}

"Responsiveness of the software product to user inputs or events in a meaningful way." [3]

\begin{tabular}{l|l} 
Completeness & {$[55]$} \\
\hline
\end{tabular}

Whether a user can complete a specified task.

\begin{tabular}{l|l} 
Fault tolerance & [3] \\
\hline
\end{tabular}

"The capability of the software product to maintain a specified level of performance in cases of software faults or of infringement of its specified interface." [3]

\section{\begin{tabular}{l|l} 
Readability & {$[3]$} \\
\hline
\end{tabular}}

Ease with which visual content (e.g., text dialogs) can be understood.

\begin{tabular}{l|l} 
Controllability & {$[41][42][43][53]$} \\
\hline
\end{tabular}

Whether users feel that they are in control of the software product.

\begin{tabular}{l|l} 
Navigability & {$[3]$}
\end{tabular}

Whether users can move around in the application in an efficient way.

\begin{tabular}{l|l} 
Simplicity & {$[54]$} \\
\hline
\end{tabular}

"Whether extraneous elements are eliminated from the user interface without significant information loss."

\begin{tabular}{l|l} 
Privacy & {$[3]$} \\
\hline
\end{tabular}

"Whether users' personal information is appropriately protected."

\begin{tabular}{l|l} 
Security & {$[3]$} \\
\hline
\end{tabular}

"The capability of the software product to protect information and data so that unauthorized persons or systems cannot read or modify them and authorized persons or systems are not denied access."

\begin{tabular}{|l|l}
\hline Quality of outcome & [55]
\end{tabular}

Measures of the quality of the outcome of the interaction

\begin{tabular}{l|l}
\hline Experts' assessment & [55]
\end{tabular}

Experts' assessment of outcomes of the interaction

\begin{tabular}{l|l}
\hline Users' assessment & [55]
\end{tabular}

Users' assessment of the outcome of interaction

\begin{tabular}{l|l} 
Preference & [56][57]
\end{tabular}

"Measures satisfaction as the interface users prefers using." [55]

Users' attitudes and perceptions 155$]$

"Users' attitudes towards and perceptions of phenomena other than the interface" [55] 